\title{
LA POSMODERNIDAD Y LAS NUEVAS TECNOLOGÍAS EN LOS CONTEXTOS EDUCATIVOS CUBANO Y BRASILEÑO
}

\author{
Juan Carlos Rodríguez Cruzl \\ Luiz Bezerra Neto²
}

\section{RESUMEN}

El trabajo aborda la categoría posmodernidad como producto de la Globalización, un nuevo proceso civilizatorio en la cual las nuev as tecnologías son su sustento y a la vez su tangencial; proceso civilizatorio que constituye solo un eslabón de concatenación y transición entre dos Eras, la que fenece de la Modernidad tardía y la que comienza con una nueva cara aún sin definir. Se valora la categoría contexto educativo, desde la perspectiva de diferentes autores y se realiza un análisis sobre las ventajas y desventajas del uso de la digitalización en la educación actual y cómo esta educación se desenvuelve en los contextos educativos cubanobrasileño, a partir de un estudio comparativo.

Palabras claves: Posmodernidad. Nuevas tecnologías. Contexto educativo. Brasil. Cuba.

\section{POSTMODERNIDADE E NOVAS TECNOLOGIAS NOS CONTEXTOS EDUCATIVOS CUBANO E BRASILEIRO}

\section{RESUMO}

O trabalho aborda a categoria pós-modernidade como produto da Globalização, como um novo processo civilizatório, no qual as nov as tecnologias são seu sustento e, ao mesmo tempo, tangenciais; Processo civilizatório que constitui só um elo de concatenação e transição entre duas Eras, a que fenece da Modernidade tardia e a que começa com uma cara nova ainda sem definir. A categoria do contexto educacional é avaliada sob a perspectiva de diferentes autores e é feita uma análise das vantagens e desv antagens do uso da digitalização na educação atual e como essa educação se desenvolve nos contextos educacionais cubanobrasileiro, com base em um estudo comparativo.

Palavras-chave: Pós-modernidade. Novas tecnologias. Contexto educacional. Brasil. Cuba.

\footnotetext{
1 Doctor en Ciencias. Universidad de Holguín, Cuba. ORCID iD: http://lattes.cnpq.br/00000002-8785-7255. E-mail: juancarlosrodriguezcruz2002@gmail.com

2 Doutor em Educação. Universidade Federal de São Carlos - UFSCar. ORCID iD: http://lattes.cnpq.br/4809-0805-9333-3472. E-mail: Ibezerra.ufscar@gmail.com
} 


\title{
POSTMODERNITY AND NEW TECHNOLOGIES IN THE CUBAN AND BRAZILIAN EDUCATIONAL CONTEXTS
}

\begin{abstract}
The work addresses the postmodernity category as a product of Globalization, as a new civilizatory process in which new technologies are its sustenance and at the same time its tangential; civilizatorio process that constitutes only a link of concatenation and transition between two Eras, the one that fenece of the late Modernity and the one that begins with a new face still without defining. The educational context category is evaluated from the perspective of different authors and an analysis is made of the advantages and disadvantages of the use of digitization in current education and how this education develops in the CubanBrazilian educational contexts, based on a study comparative.
\end{abstract}

Keywords: Postmodernity. New technologies. Educational context. Brazil. Cuba.

\section{INTRODUCCIÓN}

El discurso posmoderno ha impactado en la sociedad internacional. Esta sociedad ha estado acelerada por el proceso globalizador en la cual las nuevas tecnologías son herramientas fundamentales que le sirven de sustento. Al respecto, comentando a Valenzuela, la política posmoderna es producto de fenómenos complejos y contradictorios, que su lado positivo es el insistente recordatorio de la complejidad del mundo que habitamos, donde se barajan a la par el impacto de las nuevas tecnologías y la Era de la Información, la Globalización y la transformación cultural (Valenzuela, 2018). La posmodernidad imbrica a la Era de la información y sus principales aportes científico-tecnológicos les sirven como cimiento fundamental para su transformación. Pero, más que la Era de la información, la posmodernidad a juicio de estos investigadores que suscriben, es un proceso civilizatorio, una nueva Era del desarrollo, donde están presentes las dos categorías más esenciales que a lo largo de la historia han ido transitando de acuerdo a los estadios del desarrollo: el hombre y la naturaleza.

En esta relación hombre-naturaleza, la cultura ha jugado un papel esencial como actividad práctico transformadora que de forma consciente el hombre produce y reproduce. Por tanto, es la cultura la que ha 
moldeado, de acuerdo al grado de desarrollo, todos los procesos civilizatorios por los que ha transitado la humanidad.

Múltiples han sido los investigadores que han trabajado el concepto Posmodernidad y lo han encaminado por diferentes vertientes como: la sociología, la historia, el arte, la literatura, la filosofía...etc. Entre los principales exponentes se encuentran (Habermas, 1986); (Lipovetsky, 1986); (Harvey, 1990); (Morin, 1994); (Blanco, 1997); (Arriarán, 1997); (Anderson, 2000); (Castillo, 2005); (Palaversich, 2005); por solo citar algunos.

Los investigadores mencionados coinciden de una forma $u$ otra en que la posmodernidad ha penetrado los diferentes núcleos de la sociedad y sus límites colindantes, y se expresa en una revolución de lo cotidiano, en un desencanto, en el tiempo no del otro, si no del yo propio, en lo heterogéneo, en lo prohibido, en el narcisismo, muy distante de lo que fue el prometeísmo o sisifismo; en el desgajamiento que origina la pluralidad de formas que desvalorizan, lo que instauró la modernidad hace más de quinientos años. Según Lipovetsky ésta "es una sociedad que, lejos de exaltar los órdenes superiores los eufemiza y los descredibiliza, una sociedad que desvaloriza el ideal de abnegación estimulando sistemáticamente los deseos inmediatos, la pasión del ego, la felicidad intimista y materialista" (LIPOVETSKY, 1986, p. 54).

Penetrar en las esencias de este proceso inconcluso, al cual estos investigadores lo refrendan con el nombre de Crisis Renacentista de la Modernidad es harto complejo. ¿̇Qué se entiende por Crisis Renacentista de la Modernidad? La posmodernidad en este transcurrir de la historia, no es el fin de la historia, ni del último hombre, como sentenció el filósofo Fukuyama, sino crisis o tribulación de la modernidad que en su más avanzado desarrollo se desvanece y nace de ella un eslabón que concatena el pasado con lo nuevo que está por definir. Es la incertidumbre de un mañana que no tiene un molde al que se logre precisar todavía, pero como denomina Morín, "aún no vemos la cara de lo que está emergiendo, tenemos una manera pobre de denominarlo, el término es pos, posmoderno. Pienso que los términos pos 
y neo traducen la imposibilidad de conceptualizar verdaderamente, por ahora, la nueva cara que todavía no está formada" (MORíN, 1994, p. 67).

En esta misma línea de análisis, se considera que la posmodernidad, en proporción, es a la Modernidad lo que el Renacimiento fue al Medioevo. Si los renacentistas retomaron los valores del clasicismo griego, en detrimento de los valores creados por la larga Edad Media, que sirvieron de paradigmas y bajo los cuales se desenvolvió la sociedad occidental, ahora la posmodernidad intenta retomar algunos de esos valores, que se expresan en la multiplicidad de creencias esotéricas y, a su vez, en la asunción de códigos que relativizan el proceder consciente de los sujetos actuantes.

Se recuerda el sinnúmero de creencias que se conformaron en la Edad Media, cuyas creencias fueron perseguidas por el Tribunal del Santo Oficio, fundamentalmente, a partir de la segunda mitad del siglo XV. Téngase en cuenta también que, como herederos de las culturas Judea Cristiana y Greco Latina, la vuelta al pasado y la inmersión en esas culturas cierra e inicia un ciclo, el del devenir pasando por la Modernidad y el de proyectarse desde el hoy Posmoderno.

No quiere decir en modo alguno que la Posmodernidad sea contraria a la Modernidad o enemiga de ella o se presente, como dice Habermas, como anti-modernidad (HABERMAS, 1986). No se concuerda en este sentido. La Posmodernidad niega a la Modernidad como proceso dialéctico, en la cual, la lucha de los contrarios que ella contiene al oponerse y presuponerse originan un estadio cualitativo y cuantitativo de desarrollo. Respecto al desarrollo, Lenin señalaba que se da en espiral con avances y retrocesos (LENIN, 1978).

Un retroceso en el desarrollo de la sociedad global es propio de la dialéctica de la transformación que, en su progresión y regresión, va dejando una estela de nuevas semánticas. La posmodernidad tangencia hacia lo nuevo e interrelaciona lo más novedoso con elementos del pasado en un proceso de complejidad cultural conocido como: el eterno retorno. $Y$ es en ese eterno retorno, es en esa imbricación de pensamientos y formas que se construyen y configuran los nuevos significados y conceptos. 
La sociedad, en la búsqueda de nuevos escenarios, porque los escenarios presentes han agotado su contenido y forma, precisa de una atmósfera diferente en la que actúa, porque la actual atmósfera se percibe en proceso de expiración por el propio hastío existencial que legó el siglo XX con sus dos conflictos mundiales, la Guerra Fría y la caída del Muro de Berlín; entonces evoca el pretérito. No importa qué tiempo del pasado, pero lo evoca y lo convoca.

Sobre lo anterior, nada más atinado que la pregunta que se formuló Carlos Marx en Dieciocho de Brumario de Luis Bonaparte, donde trata sobre este tema. "¿Cómo es que hasta en la culminación del proceso revolucionario los propios revolucionarios convoquen ansiosamente a los espíritus del pasado y se apropien de sus nombres, de sus gritos de batalla y su vestimenta a fin de representar la nueva escena de la historia del mundo bajo esos disfraces vetustos y con un lenguaje prestado?" (MARX, 1986, p.254).

La construcción de significados encuentra siempre en el pasado sus antecedentes mediatos e inmediatos. En esos significados aparece lo sígnico y lo simbólico como centro del imaginario social, razón por la cual al evocar y apropiarse de sus nombres, como dice Marx, no es retornar al pasado y quedarse en el pasado, sino retornar al pasado y volver al presente para configurar los nuevos sentidos.

En resumen la posmodernidad es la mediación entre una Era que concluye y una Era que comienza; y esta mediación que comienza en las postrimerías del siglo XX y se desenvuelve hasta hoy, está acuñada por el desarrollo de las nuevas tecnologías de la información que le van marcando un nuevo rumbo a la sociedad, la cual está en permanente cambio y continuidad en interconexión con el pasado.

Recuérdese que las nuevas tecnologías son las herramientas que han permitido a la Globalización reducir el espacio y acelerar el tiempo, cuyos conceptos claves son la información y la comunicación, que permiten comprender a la sociedad actual y rubricarla con el término de Era Digital. Pero, como se está inmerso, como se dijo anteriormente, en un nuevo 
proceso civilizatorio, este es de transformación, por lo que la información va moldeando su derrotero y creando sus propias características, por lo que comentando a Castells, estas dependen del poder de quienes se benefician en cada una de las múltiples opciones que se presentan a la voluntad humana (CASTELLS, 2005).

A partir de lo expuesto se formulan dos preguntas. ¿Cómo este proceso tecno-informativo va a favorecer y a afectar a la educación? y ¿Qué papel juega en los contextos educativos cubano y brasileño, teniendo en cuenta que las nuevas tecnologías de la información y las comunicaciones son el soporte en el cual descansa el nuevo proceso civilizatorio?

Para responder a estas interrogantes se tendrá en cuenta, como premisa fundamental, un pensamiento freiriano que, a juicio de estos investigadores, es punto de partida para el siguiente análisis: "mudar a linguagem faz parte do processo de mudar o mundo" (FREIRE, 2009, p. 68).

Si Freire consideraba que cambiar el lenguaje es parte del proceso de transformar el mundo, con el desarrollo de la informatización, comienza al unísono un desenvolvimiento de las ideas y del lenguaje, hasta ahora no conocidos. El lenguaje, como constructo social, progresa en la medida que progresa también la ciencia de la Informática, cuya praxis, objetiva en los diferentes espacios de aprendizaje, permite a los educandos transformarse a sí mismos y a la vez transformar a los demás en un proceso de interrelación alumno-alumno, alumno-grupo, alumno-profesor, alumno-sociedad. Al respecto Marx señalaba, "ni las ideas ni el lenguaje constituyen un dominio propio, no son más que expresiones, manifestaciones de la vida real." (MARX Y ENGELS, 1986, p. 103). Por tanto, toda proyectividad transformativa parte de la objetividad y se concreta en la objetividad.

Tanto el lenguaje, como las nuevas prácticas tecnológicas que lo transforman y a la vez se transforman así mismas y transforman el mundo, son aportaciones concretas a la educación; y la educación, a su vez, es beneficiaria en tal sentido y en tanto tal el lenguaje la va configurando. En 
este sentido se asume lo esbozado por (CABERO, 2000) respecto a estas contribuciones:

elimina las barreras espacio-temporales entre el profesor y el estudiante; flexibiliza la enseñanza; amplia la oferta educativa para el estudiante; favorece tanto el aprendizaje cooperativo como el autoaprendizaje; individualiza la enseñanza; potencia el aprendizaje a lo largo de toda la vida; interactúa e interconecta a los participantes en la oferta educativa; adapta los medios a las necesidades y características de los sujetos y ayuda a comunicarse con su entorno y con los sujetos con necesidades educativas especiales (Citado por Meneses, 2007, p. 77).

El empoderamiento de la educación, a través de las tecnologías, entiéndase la educación como categoría socio-axiológica-tecno pedagógica, permite no solo educar a los dicentes, en los mejores valores ético-valorales de la sociedad, sino que los pone en contacto con el conocimiento científico, con lo más avanzado de la ciencia y la tecnología. Razón por la cual una educación informatizada obliga a pensar y a repensar los procesos de enseñanza-aprendizaje y, a la vez, a una continúa revaluación didáctico-pedagógica.

La didacta-pedagogía como ciencia, en su revaluación, se nutre de un arsenal de herramientas tecnológicas que le dan sentido y actualización $y$, al mismo tiempo, le permite lograr un trabajo interdisciplinario $y$ transdisciplinario con proyección tecno-educativa. Para ello se puede asumir una propuesta estratégica enfocada a dicho fin como la que brinda (BELLOCH, 2012, p. 7-8):

\footnotetext{
Diseñar estrategias educativas para favorecer la integración de recursos tecnológicos en diferentes ambientes de aprendizaje. Diseñar materiales multimedia para favorecer el proceso de enseñanza/aprendizaje. Desarrollar materiales digitales. Diseñar y evaluar software educativo. Diseñar, desarrollar y evaluar modelos de educación presencial y a distancia. Diseñar, aplicar y evaluar los recursos tecnológicos. Planificar y diseñar cursos apoyados en la tecnología. Desarrollar, implementar y evaluar cursos mediados por la tecnología.
}

Al igual que las nuevas tecnologías permiten un acercamiento al conocimiento científico y una mejor comprensión de los fenómenos espacio 
temporales, también acarrean riesgos y peligros potenciales. El primer peligro, que consideran estos investigadores, es el volumen de información que poseen los estudiantes extraídos del Internet y que estos no tengan la suficiente lucidez como para elegir los mejores contenidos.

En segundo lugar el problema de la disociación. Téngase en cuenta que el hombre se constituyó como un producto de las relaciones sociales. Recuérdese que para fecha tan temprana, como lo fue la antigüedad clásica, ya Aristóteles enseñaba que no puede considerarse un miembro sin referencias al todo, y que un miembro separado del todo no es tal miembro. Que es la comunidad la que hace hombre al hombre y que caracteriza al hombre como animal político, como animal social (ARISTÓTELES, 1994). Lo anterior fue reafirmado por Marx, cuando escribió en su sexta Tesis sobre Feverbach, que "la esencia humana es, en realidad, el conjunto de las relaciones sociales." (MARX, 1979, p. 10).

A partir del principio marxista de que "el individuo es ente social. Su manifestación de vida es manifestación de vida social. Vida individual y vida social no son distintas;" (MARX, 1975, p. 267), se ofrecen algunas de las dificultades y peligros que ofrece el uso del Internet con respecto a la sociedad. Asumiendo los argumentos de Tejedor, este considera que:

- Internet llega a todos los países, pero no, a todas las personas, aumenta las diferencias entre personas, regiones y países en vez de reducirlas.

- Si todo está en la pantalla, sin movernos de casa, pueden aparecer problemas de socialización, se puede perder el contacto social directo.

- Internet es un medio para la información pero también para la desinformación; no se distingue la información contrastada, valorada y fiable de la información falsa. Existe la posibilidad de manipular la información y difundir bulos (libertad de expresión o libertinaje), se puede hacer un uso irresponsable del medio que nos llevaría a la necesidad de regular las informaciones (TEJEDOR, 2003, p.10). 
En plena concordancia con lo que plantea este autor, se considera que la des-socialización del individuo como sujeto de la cultura en relación con los otros sujetos provoca el aislamiento, por lo que comentando nuevamente a Aristóteles, en este aislamiento solo puede vivir un animal o un dios; pero no un ser humano propiamente dicho (ARISTÓTELES, 1994).

En este mismo proceso de des-socialización, que es la individualización egocéntrica, propia de la Era posmoderna, llega la desinformación o la falsación de la información, como una forma sublime de dominación psicológica; que solo puede ser frenada con una correcta selección de los contenidos, como proceso organizado y planificado, a través de la educación institucionalizada, que permita una correcta socialización del individuo como sujeto bio-social, como sujeto de la cultura; y solo una educación para todos, con carácter tecno-didáctico, puede llegar a todos los contextos educativos y ser transmitida y, al mismo tiempo, asimilada por la mayoría de los miembros de una colectividad social.

Una sociedad sin educación es insustancial y vacía. La educación es para la sociedad su Alfa y su Omega. La educación es una síntesis cultural que se interpreta, reinterpreta y aplica al proceso de socialización, y ha permitido al hombre ser su propio creador, y reproducirse socialmente en la medida en que se culturiza y se educa. Es juicio de Oliveira, (2003, p. 52) que:

Em primeiro lugar está a educação. Evidentemente, ela cada vez toma
mais lugar em tudo que se faz. Sem educação, sem instrução, você não
tem trabalhador, não tem dirigente, não tem empresa, não tem políticos,
não tem imprensa. Então a educação é a alavanca e o motor de tudo,
ainda mais numa época de competição cada vez mais acirrada, de luta
por espaço. Enfim a educação realmente é o capital humano, não
apenas da indústria, mas de uma nação que queira ser séria. Por ela é que
vamos poder eliminar as desigualdades, diminuir a fome, a miséria, vamos
poder participar dos benefícios da sociedade...

Para que se dé realmente una educación efectiva, es preciso que exista un espacio educativo, un contexto de desenvolvimiento comprometido con las prácticas de la enseñanza y educación, y el estudiantado se sienta involucrado, se identifique legítimamente con dicho 
contexto educativo y sepa crear un sentido de pertenencia e identidad que sea originado por la sistematización del proceso, cuyo contexto sistematizado, según Lave y Wenger, considere las formas de coparticipación que logren compromisos sociales que proporcionan el contexto apropiado para que se dé el aprendizaje (LAVE; WENGER, 2003)

El contexto educativo es interpretado de diversas formas. Muchos autores lo consideran como contexto de aprendizaje y se concretan al salón de clases. Para Ortiz, el contexto del salón de clases "es el conjunto de los procesos áulicos que se viven en él, estos procesos áulicos se estructuran en tres dimensiones básicas que son: a) la estructura de las actividades que organiza el docente; b) las interacciones entre los participantes del aula que se derivan de la realización de las actividades propuestas y c) las estrategias que se utilizan para construir el significado del contenido temático. La manera en que estas tres dimensiones se orquestan es la clave para promover el aprendizaje" (ORTIZ, 2010, p.5).

Otros autores como (HATIVA, 2000; TREVISÁN, 1995; CUBERO, 2005) consideran que "el contexto se refiere al clima o contexto social adecuado para el aprendizaje, al escenario sociocultural que considera: relaciones, reglas de participación, modos de participación, actividades, estrategias de aprendizaje, modos de comunicación, motivos, metas, etc" (Citado por Ortiz, 2010, p.4)

Los autores antes mencionados se concretan al acto de enseñar y aprender, es decir, al proceso de enseñanza-aprendizaje. Pero cuando se refiere al contexto educativo, estos investigadores que suscriben, lo consideran como el espacio tanto docente como extra-docente enmarcado en el currículo educativo. Un espacio en el cual lo instructivo y lo educativo se interrelacionen con las nuevas tecnologías actuantes y generen síntesis formativas.

Entonces, ¿cómo las nuevas tecnologías se desenvuelven en los cont extos educativos cubano y brasileños?

Se toma como punto de partida lo que considera la UNESCO sobre tecnologías educativas. Según la UNESCO "la tecnología educativa es una 
aplicación sistemática de los recursos del conocimiento científico al proceso que necesita cada individuo para adquirir y utilizar conocimientos." (Citado por Fernández y Gracía, 2004, p. 313)

En el contexto educativo cubano, de forma general, las tecnologías educativas se consideran como "una concepción pedagógica innovadora que en cualquier nivel de enseñanza se realice con el propósito de transformar al hombre enseñándolo a transformar su realidad" (ADDINE, 2004, p.311). Se asume en el contexto brasileño, lo que plantea Assunción que son

"...recursos tecnológicos incorporam-se de forma crescente ao
processo ensino-aprendizagem como ferramenta de mediação
entre o indivíduo e o conhecimento auxiliando na formação
cidadão que necessita desenvolver seu potencial para atuar no
contexto ao qual está inserido" (ASSUNCIÓN, 2018, p.17).

Los criterios anteriores se relacionan y se complementan. Si en el cont exto cubano es para transformarse y transformar la realidad a través de la educación, en el contexto brasileño es para desarrollar su potencial a través del proceso de enseñanza aprendizaje en el cual actúa.

Según las constataciones de estos autores y la experiencia obtenida en el trabajo docente, en el contexto brasileño se emplea el Int ernet como recurso tecnológico. Las informaciones y los recursos que se ofrecen abren una nueva ventana que permite acceder a múltiples recursos, informaciones y comunicaciones con otros, lo que ofrece la posibilidad de acceder con facilidad a conocer personalidades de opiniones diversas, pero corriendo el riesgo de la falsación de la información.

En el contexto cubano, los estudiantes no tienen acceso al Internet en las instituciones docentes, reciben la información a través de las tecnologías de forma controlada y planificada, de acuerdo a la edad y a los programas que reciben en cada grado escolar y currículo docente, a través de juegos didácticos, software educativo, teleclases y teleconferencias. Solo los estudiantes universitarios poseen el Internet y su empleo es controlado por los servidores de la institución. Su uso es racional y su empleo para fines científicos o académicos. 
En el contexto educativo brasileño, el lenguaje de la información le permite acceder a diferentes portales y obtener una variada información reciente, que le permite una mayor actualización de los contenidos científicos. En el contexto cubano, la información llega a todos a través de las publicaciones de fuentes impresas, que se encuentran en todo el país con acceso a todos los estudiantes. Se emplea el Intranet solo con carácter didáctico-educativo.

Por tanto, teniendo en cuenta que las nuevas tecnologías de la información son parte del proceso transitorio de la Posmodernidad, la cual ésta penetra todas las ramas del conocimiento, la educación, como categoría facilitadora de este proceso, está nutrida de todo un arsenal informativo que, haciendo un uso correcto de él, le podrá permitir, con un lenguaje asequible, desarrollador y axiológico, transformar el mundo, como sentenció Freire.

\section{CONCLUSIONES}

La posmodernidad es un proceso civilizatorio, resultado del proceso globalizador en fase de transición de la modernidad tardía a una nueva fase del desarrollo que aún está por definir todavía.

Las nuevas tecnologías son el pilar en que se asienta este proceso posmoderno, proceso objetivo, indetenible e irreversible que penetra todas las ramas del conocimiento.

El uso y abuso del Internet acarrea la disociación de los sujetos sociales, proceso que origina la individualización egocéntrica, el narcisismo y el aislamiento de la comunidad que dio su origen.

La educación como categoría esencial en la sociedad se apropia de este arsenal informativo. Su empleo o uso con fines didácticos-educativos, científico $\bigcirc$ académico permite a los estudiantes aprehender los conocimientos necesarios y empoderar los correctos modos de actuación social.

El contexto educativo es el escenario en el que se desenvuelven las relaciones alumno-alumno, alumno- profesor, alumno-grupo, espacio de 
interrelaciones para la formación como categoría esencial del estudiante como sujeto socio-actuante.

En el contexto educativo brasileño existen mayores potencialidades que en Cuba para el uso de las nuevas tecnologías, producto del desarrollo tecnológico de Brasil, con respecto a Cuba. Dichas potencialidades, sin una correcta selección de contenidos, pueden acarrear la desinformación o a la falsación de estos contenidos, de acuerdo a su edad y a los programas de estudio.

En el contexto cubano, la informatización digital llega a través de un proceso planificado institucionalmente, con fines didáctico-educativo, a través de la Intranet, Software educativo, tele-clases, video-clases y teleconferencias. En el contexto universitario solo se emplea el Internet con fines científico o académico.

\section{Bibliografía}

ADDINE, F. Didáctica: Teoría y Práctica. Editorial Pueblo y Educación. La Habana, 2004.

ANDERSON, P. Los Orígenes de la posmodernidad. Anagrama. Colección Argumentos. Barcelona, 2000.

ARISTÓTELES. Metafísica. Traducción de Tomás Calvo Martínez. Editorial Gredos. Madrid, 1994.

ARRIARÁN, S. Filosofía de la posmodernidad. Crítica a la Modernidad desde América Latina. Universidad Nacional Autónoma de México. México, 1997.

\section{BELLOCH, C. Las Tecnologías de la Información y Comunicación en el} aprendizaje. Material docente [on-line]. Departamento de Métodos de Investigación y Diagnóstico en Educación. Universidad de Valencia. Disponible en http://www.uv.es/bellochc/pedagogia/EVA 1.pdf (2012).

CASTELLS, M. La Era de la Información: Economía, Sociedad y Cultura. Alianza Editorial, 2005.

CASTILLO, D. Los vertederos de la postmodernidad. Literatura, cultura y sociedad en América Latina: Dovehouse-UNAM. México, 2005.

FERNÁNDEZ RODRÍGUEZ, B.; OTERO, J. G. Tecnología educativa, ¿solo recursos técnicos? Una aproximación a la tecnología educativa. En Didáctica Teoría y Práctica. Editorial Pueblo y Educación. La Habana, 2004. 
FREIRE, P. Pedagogia da esperanza: um reencontro com a pedagogia do oprimido. São Paulo: Paz e Terra, 2009.

FUKUYAMA, F. El Fin de la historia y el último hombre. Editorial Planeta. Barcelona, 1992.

HABERMAS, J. et. al. La postmodernidad. Kairós, Barcelona. 1986

HARVEY, D. La condición de la posmodernidad. Investigación sobre los orígenes del cambio cultural. En https://flacso.edu.ec/.../Harvey-D._1990_

LENIN, V. I. Cuadernos Filosóficos. Obras Completas. Tomo 29. Editorial Progreso, 1975.

LIPOVETSKY, G. La era del vacío. Ensayo sobre el individualismo contemporáneo. Anagrama, Barcelona. 1986.

MARX, C.; ENGELS, F.Obras Escogidas en Tres Tomos. Editorial Progreso Moscú. MOSCÚ, 1986.

MARX, C. Dieciocho de Brumario de Luis Bonaparte. Obras Escogidas en Tres tomos. Editorial Progreso Moscú, 1986.

MARX, C. Manuscritos filosófico-económicos. Obras Escogidas en Tres Tomos. Editorial Progreso, 1975.

MARX, C. Tesis sobre Feuerbach, trad. castellana de Ed. Grijalbo en "Tesis sobre Feuerbach y otros escritos filosóficos", México 1970.

BENÍTEZ, G. M. Interacción y aprendizaje en la universidad. Universitat rovira i virgili ntic, isbn:978-84-691-0359-3/dl: †.2183-2007.

MORIN, E. "La noción de sujeto", en D. Freid Schintman (Ed.) Nuevos

Paradigmas, Cultura y Subjetividad, (pp. 67-85). Buenos Aires: Paidós. 1994A

OLIVEIRA, F. Política educacional brasileira em um contexto de mundialização do capital.

WWW.vece.br/.../479\%20POLÍTICA\%20EDUCACIONAL\%20BRASILEIRA\%20EM\%... 2003.

CARRIÓN, R. O. Contextos de aprendizaje.

WWW.fimpes.org.mx/phocadownload/Premios/2Ensayo2010.pdf 2010.

PALA VERSICH, D. De Macondo a McOndo. Senderos de la postmodernidad latinoamericana. Plaza y Valdés, México, 2005.

TEJEDOR, F. J. Las Nuevas Tecnologías de la Información y la Comunicación y la Investigación Educativa. Universidad de Salamanca. En

rabida.uhu.es/dspace/bit stream/handle/10272/.../b15761769.pdf?... 2003. 
GARCÍA, H. V. Neorromanticismo posmoderno o 'A dios a la Razón'. Los frutos amargos del relativismo a ultranza". Gazeta de Antropología, n 18, 2018, texto 18-03. Artículo on-line, en

http://www.ugr.es/ pwlac/G18_03Hugo_Valenzuela_Garcia.html 20

WENGER, J. L. Aprendizaje Situado. Participación Periférica Légitima. México: UNAM. 2003.

Recebido em: 05 de novembro de 2018.

Aprovado em: 15 de fevereiro de 2019. 